\title{
BİRECİK BARAJ GÖLÜ HAVZASI (ŞANLIURFA) VE HAZAR GÖLÜ(ELAZIĞ) OSTRACODLARI (CRUSTACEA) HAKKINDA ÖN ÇALIŞMA
}

\section{Oya ÖZULUĞ $\breve{~ N i l a y ~ D O ̈ K U ̈ M C U ̈ ~}^{2}$}

\section{ÖZET}

Bu çalışmada Birecik Baraj Gölü Havzası ve Hazar Gölü'nden alınan örnekler değerlendirilmiş; sonucunda, Birecik Baraj Gölü Havzası'ndan 11 tür (Darwinula stevensoni (Brady \& Robertson,1870); Candona neglecta Sars, 1887; Candona angulata Müller, 1900; Fabaeformiscandona sp.; Pseudocandona cf albicans; Cryptocandona sp.; Ilyocypris sp.; Heterocypris salina (Brady, 1868); Potamocypris sp.; Limnocythere inopinata (Baird, 1843); Kovalevskiella sp.) ve Hazar Gölü'nden 3 tür (Candona neglecta Sars, 1887; Candona sp.; Limnocythere inopinata (Baird,1843)) bulunmuştur. Bu çalışma ile bildirilen türler Birecik Baraj Gölü Havzası ve Hazar Gölü için ilk kez kayıt edilmektedir.

Anahtar kelimeler: Birecik Baraj Gölü, Hazar Gölü, Ostracoda, Taksonomi.

\footnotetext{
1 İstanbul Üniversitesi, Fen Fakültesi, Biyoloji Bölümü, 34134, Vezneciler / İSTANBUL oozulu@istanbul.edu.tr

${ }^{2}$ Mimar Sinan Mahallesi, Bulgurlu Mescid Sokak, No:17, 34672, Üsküdar / İSTANBUL
} 


\title{
A PRELIMINARY STUDY ON OSTRACODA (CRUSTACEA) OF THE BİRECIKK RESERVOIR BASIN (ŞANLIURFA) AND LAKE HAZAR (ELAZIĞ)
}

\begin{abstract}
In this study, the samples which collected from The Birecik Reservoir Basin and Lake Hazar were examined. As a result, 11 species from Birecik Reservoir Basin (Darwinula stevensoni (Brady \& Robertson,1870); Candona neglecta Sars, 1887; Candona angulata Müller, 1900; Fabaeformiscandona sp.; Pseudocandona cf albicans; Cryptocandona sp.; Ilyocypris sp.; Heterocypris salina (Brady, 1868); Potamocypris sp.; Limnocythere inopinata (Baird,1843); Kovalevskiella sp.) and 3 species from Lake Hazar (Candona neglecta Sars, 1887; Candona sp.; Limnocythere inopinata (Baird, 1843)) were found. All of these species are new records for The Birecik Reservoir Basin and Lake Hazar.
\end{abstract}

Keywords: The Birecik Reservoir, Lake Hazar, Ostracoda, Taxonomy.

\section{GÍRIŞ}

Ostracodlar tüm yumuşak dokuyu kaplayan $\mathrm{CaCo}_{3}$ yapıda, iki parçalı kabukları olan tatlı su, deniz ve acı sular gibi farklı ortamlarda yaşayabilen canlılardır. Öldükten sonra fosil bıraktıklarından dolayı taksonomik çalışmalar yanında, paleontolojik incelemeler için de uygun materyal olma özelliği taşırlar.

Kimi ostracod türlerinin ortamlara göre seçici davranması; onların bazı ekolojik alanlarda "biyoindikatör" olarak kullanılmalarını sağlamaktadır. Kambriyenden beri varlıklarını sürdüren bu canlılar bölgenin zoocoğrafik özelliklerini ve geçmişini yansıtması bakımından da önemlidir. Bilindiği gibi buzul çağlarında Anadolu birçok türe barınak olmuştur. Anadolu'nun bugünkü iç suları kökeninin Orta Miyosen-Pliyosen dönemlerinde var olan “İç Anadolu Göl Sistemi” ne dayandığı bilinmektedir (Demirsoy, 2008). Anadolu faunası, batıda nehirlerinin çıktığı yerden, doğuda Van Gölü’ne kadar, kuzeyde Kuzey Anadolu dağ dizisi, güneyde Toroslarla sınırlanmış 
“İç Anadolu Göl Sistemi” düşünüldüğünde kambriyenden beri varlıklarını sürdüren ostracodlar da önem kazanmaktadır.

Bu çalışmada Şanlıurfa ile Gaziantep illeri arasında yer alan Birecik Baraj Gölü ve bu göle su taşıyan dere ve pınarlardan oluşan göl havzası ile Elazı ̆̆ ilinde bulunan Hazar Gölü'nden ostracod faunasını belirlemek için toplanmış örnekler değerlendirilmiştir. Birecik Baraj Gölü, Fırat nehri üzerine inşa edilmiştir. Zeugma Antik Kenti'nin bir kısmı bu baraj gölünün altında kalmıştır. Hazar Gölü ise Doğu Anadolu Bölgesinin yukarı Fırat Bölümü’nde yer alır. 70 km2'lik bir alanı kaplayan gölün derinliği 150-216 m'dir (Erman vd., 2006).

Birecik Baraj Gölü ve bu göle su sağlayan dereler ile Hazar Gölü'nün Anadolu İç Su Sistemi'nden bugüne ulaşmış olmasının yanı sıra tarihsel özellikleri de düşünüldüğünde faunal çalışmalarda bölgenin önemi bir kat daha artmaktadır. Bu bölgelerde yapılan çalışmalara baktığımızda Hazar Gölü'nün su kenesi ile Copepoda ve Cladocera faunası ve bentik faunası hakkında birkaç çalışma bulmak mümkündür [Erman vd., 2006; Tellioğlu ve Şen, 2001; Şahin ve Baysal, 1972]. Birecik Baraj Gölü hakkında ise omurgasızlara ait herhangi faunal bir çalışmaya rastlanmamıştır.

Yapılan bu ön çalışmanın amacı; tarihsel ve faunal bakımdan önem taşıyan bu bölgenin ostracod faunası yönünden de incelenmesidir. Bu amaca uygun olarak Birecik Baraj Gölü Havzası ve Hazar Gölü’nden elde edilmiş örnekler değerlendirilmiştir.

\section{MATERYAL VE YÖNTEM}

İstanbul Üniversitesi Zooloji Müzesinin Koleksiyon Kısmında, 10 Eylül 2003 y1lında Hazar gölünden; 11, 22 ve 23 Temmuz 2004 tarihinde Birecik Baraj Gölü ve Havzası'ndan toplanarak cam kavanozlar içerisinde $\% 70$ alkol ortamında muhafaza edilen sediment örnekleri incelenmiştir.

Örneklemenin yapıldığg Hazar Gölü, Elazığ kentinin güneydoğusunda yer alır. Tektonik bir göl olup eliptik şekle sahiptir. Uzunluğu $20 \mathrm{~km}$, en geniş bölümü ise $5.4 \mathrm{~km}$ olarak bildirilmiştir (Ünlü vd., 2008). Birecik Baraj Gölü Şanlıurfa ile Gaziantep illeri sınırında yer almaktadır. Gölün 
yanı sıra bu göle su sağlayan Fıstıközü Köyü Pınarı, Değirmendere, Kıço Pınarı, Kamışıı Köyü Pınarı gibi pınar ve derelerden de örnekleme yapılmıştır. Baraj gölünden Ostracoda’ya ait örnek bulunamamasına karşın; göl havzasından elde edilen materyalde ostracodlar bulunmuştur.

Materyalin fiksasyon sıvısı \%70 etil alkol değişimi ile tazelenmiştir. Ostracodlar sedimentten Stereozoom diseksiyon mikroskobu altında ayıklandıktan sonra, elde edilen Ostracoda'ya ait örneklerin laktofenol + Oranj- G kullanılarak geçici preparatları yapılmıştır. Taksonomik incelemede kabuk morfolojisi ve ekstremite özelliklerinden yararlanılmıştır. Tür tayinlerinde ve taksonomik sıralamada kaynak olarak Meisch, (2000) kullanılmıştır. Bölgedeki bulunuş sıklığı hesap edilirken Sıklık=Türün bulunduğu istasyon sayıs1/Toplam istasyon sayısı X 100 formülü kullanılmıştır (Kazanc1 ve Dügel, 2000).

\section{BULGULAR}

Bu çalışmada Hazar Gölü ile Birecik Baraj Gölü ve bu baraja su getiren pınarlardan toplanmış olan materyallerin incelenmesi sonucu bölgeden 12 ostracod türü bulunmuştur. Çalışma alanına ait istasyon bilgileri, bu istasyonlardan bulunan türler ve türlerin çalışma alanında gösterdiği dağılım ile bulunma sıklıkları kısaca aşağıda tablo halinde verilmiştir (Tablo-1). 
Tablo 1.Türlerin Birecik baraj gölü havzası ile Hazar gölü'ndeki istasyonlara göre dağılımı, istasyonlara ait toplam tür sayıları ve bölgedeki yayılışları ile bulunma sıklıkları.

Table 1. Distribution of the species in Birecik reservoir basin and lake Hazar, total specimen number and distribution belonging to stations and frequency

\begin{tabular}{|c|c|c|c|c|c|c|c|c|c|c|}
\hline & $\begin{array}{l}\text { Bir } \\
\mathrm{Ha}\end{array}$ & $\begin{array}{l}\text { ecik } \\
\text { Zzas }\end{array}$ & Bar & aj Gi & ölü & & $\begin{array}{l}\mathrm{Ha} \\
\text { Gö }\end{array}$ & $\begin{array}{l}\text { zar } \\
\text { lü }\end{array}$ & & \\
\hline & 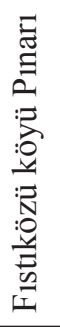 & 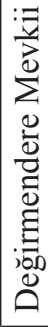 & 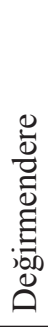 & 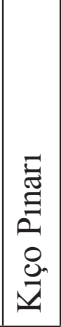 & 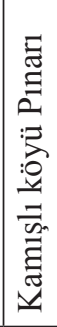 & 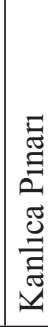 & 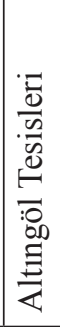 & 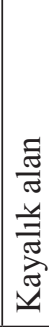 & 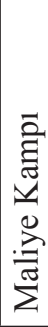 & $\begin{array}{l}\ddot{\exists} \\
\ddot{\exists} \\
\widetilde{\sigma}\end{array}$ \\
\hline Darwinula stevensoni & & $*$ & & $*$ & $*$ & & & & & $\% 33$ \\
\hline Candona neglecta & & & $*$ & & $*$ & & & & $*$ & $\% 33$ \\
\hline Candona angulata & & & & & $*$ & & & & & $\% 11$ \\
\hline Candona sp. & & & & & & & $*$ & $*$ & & $\% 22$ \\
\hline Fabaeformiscandona sp. & & & & & & $*$ & & & & $\% 11$ \\
\hline Pseudocandona cf albicans & & $*$ & & & & & & & & $\% 11$ \\
\hline Cryptocandona sp. & & & & $*$ & & & & & & $\% 11$ \\
\hline Ilyocypris sp. & & & $*$ & & & & & & & $\% 11$ \\
\hline Heterocypris salina & & & & & & * & & & & $\% 11$ \\
\hline Potamocypris sp. & & * & $*$ & $*$ & & & & & & $\% 33$ \\
\hline Limnocythere inopinata & $*$ & & $*$ & & & & $*$ & $*$ & $*$ & $\% 55$ \\
\hline Kovalevskiella sp. & & & $*$ & & & & & & & $\% 11$ \\
\hline Toplam tür sayısı & 1 & 3 & 5 & 3 & 3 & 2 & 2 & 2 & 2 & \\
\hline
\end{tabular}

\section{TARTIŞMA VE SONUÇ}

Bulunan 12 ostracod türünden $D$. stevensoni kozmopolit olarak bilinen türdür. Çalışmamızda ise sadece Birecik Baraj Gölü’ne dökülen Kıço, Kanlıca ve Kamışlı Köyü pınarında bulunmuştur. Anadolu'dan daha önce 
Diyarbakır Kabaklı su kaynağından (Gülen vd. 1997), su kaynakları bakımindan zengin olan Bolu bölgesinden ( Külköylüoğlu, 2005; Dügel vd., 2008) ve yer altı suları ile beslenen Eğirdir Gölü (Özuluğ vd., 2001) ile Meyil ve Acı göl (Konya-Karapınar )'den (Akdemir, 2004) bildirilmiştir. Anadolu'da yaygın olarak bilinen bu türün, yayılış alanı içinde bulunduğu görülmüştür.

C. neglecta türü, geniş yaşam toleransı ile birçok su ortamında yaşayabilen bir türdür. Hem Anadolu hem de Trakya'da yaygın olarak bilinmektedir (Özuluğ vd., 2001; Özuluğ ve Yaltalıer, 2008).

Heterocypris salina da kozmopolit bir türdür. Limnocythere inopinata çevresel şartlara gösterebildiği geniş tolerans nedeni ile birçok su ortamında rastlanabilen bir türdür. Bazı su kaynaklarında erkek bireylerin nadir olduğu bildirilmiştir (Meisch, 2000). Hazar Gölü’nde bulunan popülasyonda erkek bireylerin sayısı yüksek oranda bulunmuşur.

Bulunan türler arasında çok nadir rastlanan bir cins olan Kovalevskiella sp.' nin yayılışı yeni yeni ortaya çıkmaktadır. Ülkemizden bu cinse ait bir tür Kovalevskiella bulgarica bilinmektedir. Bu tür ilk kez Kırklareli'ndeki Rezve deresinden bildirilmiştir (Özuluğ ve Yaltalıer, 2008). Bu cinsin ülkemizdeki yayılımı Zonguldak (Danielopol, 1980), Kadıköy Baraj Gölü Tekirdağ (Özuluğ, 2000). olarak görülmektedir. Çoğunlukla kabuk olarak rastlanan bu cinsin tür seviyesindeki ayrımı sadece Rezve deresinden elde edilen örnek sayesinde olmuştur. Bu çalışmamızda da sadece kabuk olarak bulunmuş olan Kovalevskiella cinsine ait örneğin türü belirlenememiştir; fakat cinsin yayılım alanı güneydoğuya doğru genişletilmiştir. Birecik Baraj gölü ve havzasına ait Ostracoda faunasına yönelik daha önceki yapılan ayrıntılı bir çalışma yoktur. Hazar Gölü'ne bakıldığında sadece 3 tür bulunmuştur. 1972 yılında yapılan Hazar gölü dip faunası ve yayılışları adlı çalışmada bir ostracoda türü Candona muelleri bildirilmiştir (Şahin ve Baysal, 1972). Çalışmamızda bu türe rastlanamamıştır fakat göle ait bilinen tür sayısı arttırılmıştır.

Bölgeyi Ostracoda'ya ait tür sayısı bakımından ele aldığımızda, 5 tür ile Değirmendere zengin bir istasyon olarak görülmektedir (Tablo.1). Bölgede bulunan türlerin sıklıkları incelendiğinde \%55 ile L. inopinata en 
s1k rastlanan türdür. $D$. stevensoni ve $C$. neglecta türleri ise $\% 33$ s1klıkta bulunmuştur (Tablo.1). L. inopinata türü genellikle baraj göllerinde ve derin göllerde bulunmaktadır (Meisch, 2000). Bu türün bulunduğu beş istasyondan üçünün Hazar Gölü'ne ait olduğunu görüyoruz. Bu durum $L$. inopinata'nın bilinen ekolojik yayılış alanı içerisinde bulunduğunu göstermektedir.

Hazar Gölü, fiziksel ve kimyasal özellikleri bakımından diğer göllerden farklılık göstermektedir (Ünlü vd., 2008). Ayrıca çalışma bölgesinde yer alan su kaynaklarının Orta Miyosen-Pliyosen dönemlerinde var olan İç Anadolu Göl Sistemi'nden günümüze kadar ulaşması sonucu, bu bölgedeki su kaynaklarının ve Hazar Gölü'nün önemi artmaktadır. Bu nedenle gölün su özellikleri ile birlikte daha ayrıntılı çalışmaların yapılması planlanmaktadır.

Yapılan çalışmada kimi örneklerin genç birey olması kimilerinin örneklerin yumuşak dokusundaki bozulmalar nedeni ile bazı cinslerin tür tayinleri yapılamamıştır. Buna rağmen yer altı su sistemleri ile ilişkili olduğu bilinen Darwinula ve Kovalevskiella cinslerinin bulunması ile bölgenin ayrıntılı olarak çalışılması gerekliliği bu ön çalışma ile ortaya koyulmuştur. Bu çalışma, Birecik baraj gölü havzasına ait ostracodlar hakkında ilk çalışma olması açısından da ayrıca önemlidir.

\section{KAYNAKLAR}

Akdemir, D. (2004). Konya-Karapınar Krater Göllerinin Ostrakot Faunası. Yüksek Lisans Tezi. Danışman Özuluğ, O., İ.̈̈. Fen Bilimleri Enstitüsü, İstanbul.

Danielopol, D. L. (1980). An essay to assess the age of the freshwater interstitial ostracods of Europe, Bijdragen Tot De Dierkunde, 50 ,2, 243291.

Demirsoy, A. (2008). Genel Zoocoğrafya ve Türkiye Zoocoğrafyas1 "Hayvan Coğrafyası". Meteksan, Ankara, s. 305-309. ISBN: 978-9757746-33-1.

Dügel, M., Külköylüoğlu, O. ve Kılıç, M. (2008). Species assemblages and habitat preferences of Ostracoda (Crustacea) in Lake Abant (Bolu,Turkey). Belg. J. Zool., 138(1): 50-59. 
Erman, O., Tellioğlu, A., Orhan, O., Çitil, C. ve Özkan, M. (2006). Hazar Gölü ve Behremaz Çayı (Elazığ) Su Kenesi (Hydrachinidia: Acari) Faunası ve Mevsimsel Dağılımı. Fırat Üniv. Fen ve Müh. Bil. Der. 1, 1-10.

Gülen, D., Özuluğ, O. ve Bilgin, F. (1997). Kabaklı Kaynağı(Diyarbakır) Ostracod (Crustacea) Faunası. XIII. Ulusal Biyoloji Kongresi Tebliğleri, İstanbul, 162-172.

Kazanc1, N., Dügel, M. (2000). An evaluation of the water quality of Yuvarlakçay Stream in thi Köyceğiz-Dalyan protected area, SW Turkey. Turkish Journal of Zoology, 24, 69-80.

Külköylüoğlu, O. (2005). Ecology and phenology of freshwater ostracods in Lake Gölköy (Bolu, Turkey). Aquatic Ecology, 39, 295-304.

Meisch, C. (2000). Freshwater Ostracoda of western and central Europe. In Schwoerbel J and Zwick P, Suesswasserfauna von Mitteleuropa: Spektrum Akademischer Verlag, Heidelberg. 8/3.

Özuluğ, O. (2000). Trakya Bölgesi Ostracod (Crustacea) Faunas1. Doktora Tezi, Danışman Gülen, D., İstanbul Üniversitesi Fen Bilimleri Enstitüsü, İstanbul.

Özuluğ, O. ve Yaltalıer, S. (2008). A preliminary study on the Rezve stream and a new record for Ostracoda(Crustacea) fauna of Turkey. IUFS Journal of Blology, 67, 1, 93-96.

Özuluğ, O., Kubanç, N. ve Gülen, D. (2001). Ostracod (Crustacea) Fauna of Lake Eğridir (Isparta). Turkish Journal of Zoology 25, 421-425, Ankara.

Şahin, Y. ve Baysal, A. (1972). Hazar Gölü Dip Faunası ve Yayılışları. İst. Üni. Fen Fak. Hidrobiyoloji Araş. Enst. İçsular Araş. Kısmı. İst. Üniv. Fen Fak. Basımevi, 9, 1-33.

Tellioğlu, A., Şen, D. (2001). Hazar Gölü (Elazı̆̆) Copepoda ve Cladocera Faunasının Mevsimsel Dağılımı. G. Ü. Gazi Eğitim Fakültesi Dergisi. 21, 2, 7-18.

Ünlü, A., Çoban, F. ve Tunç, M.S. (2008). Hazar Gölü Su Kalitesinin Zamanla Değişimi. Doğu Anadolu Bölgesi Araştırmaları Dergisi. 6, 2, 93 101. 